\title{
Dilemas da política de distribuição de medicamentos antirretrovirais no Brasil
}

\author{
Policy dilemmas in providing antiretroviral treatment in Brazil
}

Regina Ferro do Lago ${ }^{1}$ Nilson do Rosário Costa ${ }^{2}$
${ }^{1}$ Instituto de Estudos em Saúde Coletiva,

UniversidadeFederal do Rio de Janeiro. Praçajorge M achado M oreira s/ $n$ ㅇ, Ilha do Fundão, Cidade Universitária. 21944-970 Rio deJaneiro RJ. regina.ferro.lago@iesc.ufri.br ${ }^{2}$ Departamento deCiências Sociais, Escola Nacional de Saúde Pública Sergio Arouca, Fundação O swaldo Cruz.
Abstract This paper addresses institutional constraints that have affected Brazilian politics regarding provision of anti-retroviral treatment (ART) to HIV/Aids patients. Weanalyzed thenormative conflict resulting from international agree ments on intellectual property rights, especially patent protection, and the constitutional rights of Brazilian patients to universal and free access to ART. These constraints have not substantially changed the Brazilian public policy yet, but they may impact the future sustainability of this policy. As the main barrier to the production of patented drugs is not technological but institutional, Brazilian government faces a dilemma. It may either abide by existing monopolistic restrictions or it may incite competitiveness of domestic industries and developing countries in the pharmaceutical market.

Key words Pharmaceutical policy, Antiretroviral drugs, $\mathrm{H}$ ealth policy
Resumo Este artigo trata dos constrangimentos institucionais que têm afetado a política brasileira de provisão de medicamentos contra a Aids. É analisado o conflito normativo observado na política de Aids entre as regras internacionais da propriedade intelectual, em especial a proteção de patentes, ea orientação de acesso universal e gratuito a medicamentos, que norteia a política brasileira. Esses constrangimentos não têm tido sucesso em alterar a configuração distributiva da política pública brasileira; contudo, vêm alterando as condições de sustentabilidade da política pública. Considerando que a principal barreira para a produção de medicamentos protegidos por patente é institucional e não tecnológica, o governo brasileiro tem enfrentado o dilema da tomada de decisão entrea manutenção da regra de monopólio ou o incentivo à competitividade que permita o posicionamento eficiente dos produtores nacionais e dos países emergentes.

Palavras-chave Assistência farmacêutica, Me dicamentos antirretrovirais, Política de saúde 
Introdução

O objetivo deste artigo é descrever os dilemas da política de distribuição gratuita e universal de medicamentos para Aids no Brasil. Esta política de assistência farmacêutica tem sofrido um crescente constrangimento por força das mudanças no contexto internacional quanto aos medicamentos. Ainda assim, esses constrangimentos não têm tido sucesso em alterar a configuração distributiva da política pública brasileira ${ }^{1}$.

0 debateinternacional sobreo desenvolvimento de políticas sociais destacou os constrangimentos supranacionais sobre a decisão doméstica em política pública. 0 contexto da política de assistência farmacêutica para Aids exemplifica o efeito de regras institucionais formais sobre as decisões dos atores individuais - no caso, as elites nacionais. Segundo N orth², as instituições modelam as condições para a ação coletiva. 0 principal papel das instituições na sociedadeéreduzir a incerteza através do estabelecimento de uma estrutura estável embora não necessariamente eficiente - para a interação humana. As regras formais e os constrangimentos informais trazem importantes implicações para as decisões sobre políticas públicas, como é o caso da política de assistência farmacêutica no Brasil e nas economias periféricas.

Como operam as instituições em situações em que existe conflito normativo sobre os valores que orientam as decisões políticas? A política de proteção social éum terreno fértil para a percepção de conflitos normativos. Ainda assim, existem poucos estudos que tenham gerado evidências em relação aos conflitos normativos entre políticas nacionais universalistas e as regras supranacionais.

Os constrangimentos supranacionais foram identificados nas políticas de natureza macroeconômica. M elo e Costa ${ }^{3}$, ao estudarem a dinâmica da difusão da agenda de reformas macroeconômicas, identificaram umaforte aderência ao ajuste fiscal das décadas de 80-90 por parte das elites domésticas pelo mecanismo de policy bandwagoning ("efeito ônibus") em políticas. Este consiste no processo de adaptação, pelos governos nacionais, de políticas internacionalmente bem sucedidas.

São poucos os exemplos do efeito ônibus em políticas aplicadas às políticas setoriais, exceto para os casos das reformas da saúde propostas pelas agências nacionais. 0 caso da política brasileira de distribuiç̧ão de medicamentos contra Aids oferece uma oportunidade de avaliação da relação entre constrangimentos gl obais e decisão nacional de política pública. Na experiência brasileira, a orientação doméstica produzirá um conflito normativo em relação às regras do comércio internacional para a política de assistência farmacêutica, gerando um espaço de inovação na agenda da política pública brasileira.

Nesteartigo, édiscutida a principal matriz de conflito normativo internacional queinterferena política brasileira de oferta de antirretrovirais (ARV). Esta matriz está relacionada aos acordos internacionais que foram ratificados pelo Brasil no começo de 1990 e que redefiniram as regras do jogo para as questões de propriedade intelectual e de direito de patentes. Os efeitos dessas novas regras sobre a política de medicamentos têm sido extremamente complexos.

A despeito de o Brasil não oferecer cobertura universal de medicamentos para toda a população, por força das restrições fiscais e da dinâmica do mercado de medicamentos, determinados grupos de pacientes construíram uma posição extremamentediferenciada no acesso ao financiamento público. Esteéo caso da política brasileira de distribuição de medicamentos para a Aids.

Os gastos do M inistério da Saúde com assistência farmacêutica evidenciam essa situação. No período de 2002 a 2005, o crescimento total dos gastos foi de $84 \%$, passando de $R \$ 2,435$ bilhões para $\mathrm{R} \$ 4,5$ bilhões. Porém, esta elevação não se deu de forma homogênea. Os medicamentos de dispensação em caráter excepcional, destinados às patologias raras ou tratamentos de alto custo ou de longa duração, registraram o aumento percentual de $170 \%$. Os gastos com medicamentos de programas estratégicos, como os de tuberculose, os imunobiológicos e as drogas antiHIV/Aids, cresceram $80 \%$. Já o dispêndio com os medicamentos para atenção básica (analgésicos, anti-inflamatórios, antibacterianos eoutros) cresceu ligeiramenteabaixo, $68 \%{ }^{4}$.

\section{A política brasil eira de distribuição de medicamentos antirretrovirais}

O Brasil foi o primeiro país de renda média a oferecer tratamento com medicamentos distribuídos gratuitamente para Aids. Embora as estraté gias empreendidas sejam múltiplas, a distribuição de ARV éa que apresenta maior visibilidade. Foi justamente a face mais conhecida da política brasileira queproduziu um ponto de conflito com as orientações normativas internacionais.

Desde 1988, o Sistema Único de Saúde (SU S) tem distribuído medicamentos para o tratamen- 
to de infecções oportunistas. Em 1991, iniciou-se a distribuição do antirretroviral zidovudina. Em 1996, a Lei n ${ }^{\circ} .313^{5}$ estabeleceu a oferta universal e gratuita deARV aos portadores do HIV e doentes de Aids que preenchem os critérios estabelecidos no documento de consenso terapêutico em HIV/Aids do M inistério da Saúde (MS). Recomenda-setratamento para indivíduos assintomáticos com contagem de linfócitos T-CD 4+ abaixo de 350 células $/ \mathrm{mm}^{3}$ e pessoas sintomáticas, independentemente dos parâmetros imunológicos.

Estima-se que haja 600 mil pessoas infectadas pelo vírus HIV no Brasil. Destas, cerca de 180.000 recebem medicamentos contraAids. Desde a sua implementação, novos medicamentos foram incorporados à cesta pública. São oferecidas no país quatro classes terapêuticas de ARV: inibidor da transcriptase reversa análogo de nucleosídeo ou nucleotídeo (ITRN); inibidor da transcriptase reversa não análogo de nucleosídeo (ITRNN); inibidor da protease (IP) e inibidor defusão. A partir de 2008, um novo inibidor da protease seria incluído, e o M inistério da Saúde passaria a distribuir 18 medicamentos antirretrovirais através do SUS. Destes, oito seriam produzidos localmente edez seriam importados. A Figura 1 mostra os 17 itens distribuídos até 2007, organizados pelo ano da inclusão.

A oferta universal e gratuita de medicamentos representa um desafio do ponto de vista político, financeiro e logístico que, para um país do tamanho do Brasil, não pode ser menosprezado. Do ponto de vista político, as pressões do movimento social foram fundamentais para a aprovação da Lei no 9.313. No polo oposto, alguns setores da sociedade criticaram a magnitude dos recursos dedicados a uma doença, com número de pacientes relativamente pequeno, em um país onde há endemias e muitas outras necessidades em saúde ${ }^{6}$.

Uma crítica adicional referia-se ao fato deque uma economia periférica não teria infraestrutura e capaci dade de gestão suficientes para garantir a adesão à medicação, o que levaria a altos níveis de resistência primária. Ainda assim, as posições favoráveis à política predominaram no debate interno. No momento atual, as críticas arrefeceram ante os aspectos positivos exibidos pela política brasileira.

Dentre os resultados positivos, evidenciamsea redução da mortalidadeem $40 \%$ a $70 \%$ entre 1997 e2003; a diminuiç̧ão da morbidadeem mais de 60\%; a economia de 360.000 hospitalizaçõesindicando redução em $85 \%$ - e a estimativa de que 58.000 casos de Aids foram evitados. Esses resultados estão associados a um aumento de dez vezes na sobrevida após o diagnóstico deAids (de seis para 58 meses) 7 .

Desde o seu início, a despesa total com os ARV consumiu mais de US\$ 1 bilhão. No entanto, estudos mostram que os gastos evitados com despesas ambulatoriais, hospitalizações, seguros, absenteísmo e perda de mão de obra são da ordem de US\$ 2 bilhões ${ }^{1}$. Os ganhos relativos à afirmação dos direitos humanos são de difícil mensuração, mas de grande importância. Ademais, a dicotomia "prevenção versus tratamento" enfraqueceu-se, eo acesso às drogas éreputado pela Organização Mundial da Saúde(OM S) e a UNAids como elemento central em estratégias efetivas de combate ao HIV e à Aids's.

Um marco importante na história da política foi a decisão do governo brasileiro, em 1993, de contrair um empréstimo com o Banco Mundial para financiar as atividades de um programa de prevenção e controle?. Este não incluía o acesso

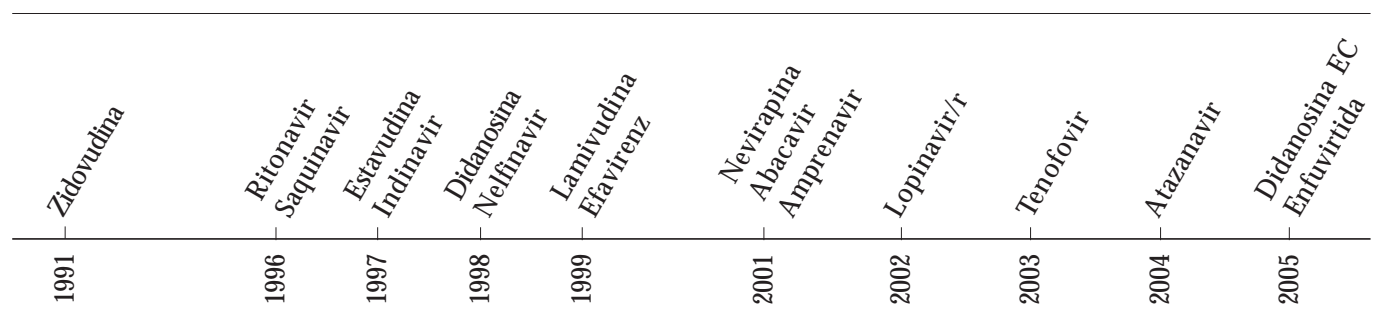

Figura 1. ARV distribuídos no Brasil por ano de inclusão (2007).

Fonte: Programa Nacional deDST eAids. 
universal ao tratamento medicamentoso, que é sustentado por recursos nacionais. Sabe-se que o Banco M undial não aprovava as iniciativas brasileiras defornecimento de medicamentos contra a Aids. A ideia de que a provisão de serviços e bens de atenção à saúde seja direito universal não era partilhada pelo banco. As recomendações, principalmente para os países pobres, estavam centradas na provisão de bens públicos puros, ou seja, mais em prevenção do queno tratamento $0^{3,10}$. Todas as fases do empréstimo do Banco M undial contaram com valores de contrapartida do governo brasileiro, queaumentaram a cada empréstimo. 0 Gráfico 1 mostra o gasto total do governo brasileiro na política contra as doenças sexualmentetransmissíveis (DST) eaAids no período de 1997 a 2001, em comparação com os recursos provenientes do Banco Mundial para o programa de prevenção e controle.

No debate pontual com o Banco Mundial, ficou evidentea contradição entrea orientação universalista da Constituição Federal, na qual se inclui 0 acesso a medicamentos ARV, e o foco dos empréstimos. 0 crescimento das despesas governamentais faria a diferença da experiência brasileira em relação aos programas implementados em outros países em desenvolvimento cujos gastos públicos são, comparativamente, pequenos ${ }^{11}$.
Assim, embora tenha representado uma alavanca aos esforços empreendidos, a participação do Banco M undial tem sido residual na política brasileira. Essa situação se traduziu na autonomia nacional quanto às decisões sobre estratégias de ação, alocação dos recursos e implementação de diretrizes. A posição doméstica de conflito normativo em face das orientações internacionais e gerais do Banco M undial ratifica o caráter endógeno da decisão sobre a oferta de medicamentosARV.

Oportunidade política, ação intersetorial, capacidade técnica, autonomia decisória do programa e mobilização social conformariam um elenco articulado de iniciativas políticas e técnicas que caracterizariam a política brasileira de resposta à epidemia ${ }^{11-13}$.

Foi no contexto social epolítico da década de 80, marcado pelo retorno à democracia e pela emergência de nova agenda para áreas como saúde e educação, que se iniciaram as ações de controle da Aids. Nessa mesma época se iniciou o movimento da Reforma Sanitária, que preconizava a democratização das políticas de saúde e o direito à saúde como direito de todos.

Defato, a Constituição Federal de 1988 estabelece a saúde como direito, e pouco depois 0 SUS é criado. Portanto, o surgimento da Aids

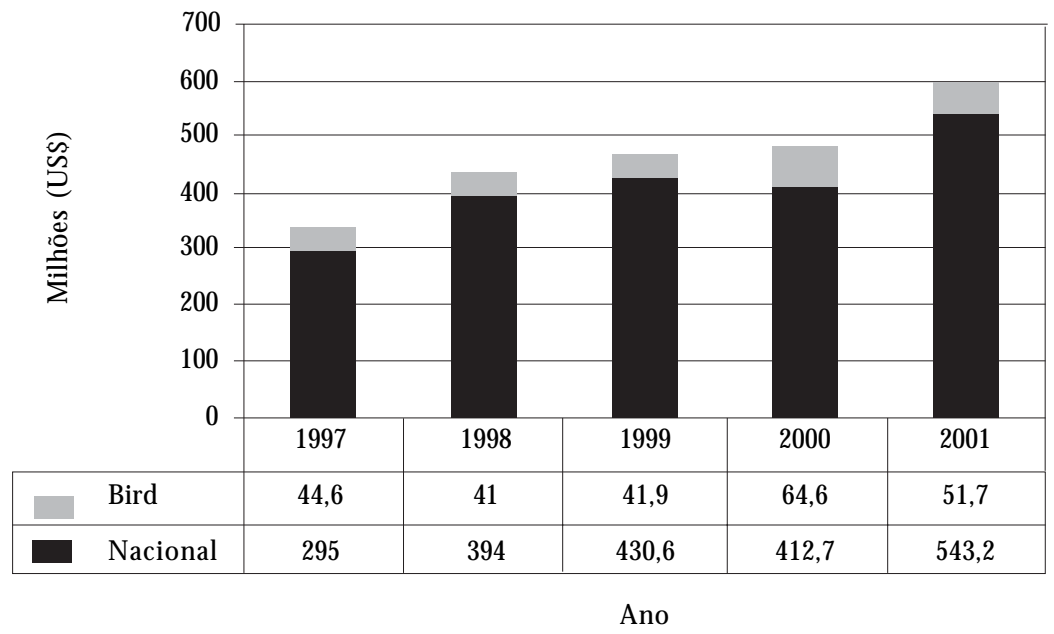

Gráfico 1. Gastos do governo brasileiro e do Banco Mundial em DST e Aids (1997-2001). 
coincide com uma atmosfera predisponente ao debate sobre a defesa dos direitos humanos e a ampliação do direito à saúde. Essa atmosfera favoreceu a mobilização da sociedade, que pressionou as autoridades sanitárias em favor da tomada demedidas para o controleda Aids. M ais do que pressão, 0 ativismo social gerou uma forte parceria com o setor governamental.

Apesar dos benefícios proporcionados pela política brasileira, a sustentabilidade do tratamento medicamentoso permaneceem questão. Alguns estudos, como os de Nunn et al. ${ }^{14}$ e Grangeiro et al. ${ }^{15}$, identificam uma grande el evação dos gastos em 2005, queinterrompeu a sériehistórica de declínio eestabilização iniciada em 1999. 0 declínio no período de 1999 a 2001 se deveu, provavelmente, à produção local de ARV sem proteção patentária, mesmo diante do crescimento no número de pacientes. A estabilização dos gastos de 2001 a 2005 deveu-setambém às negociações para redução de preço das drogas importadas empreendidas pelo MS. 0 aumento em 2005 pode ter sido gerado pelas compras de medicamentos importados. Além do crescimento do número de pessoas com HIV/Aids em tratamento, isso se deveu ao surgimento da resistência viral. Esta última gera a necessidade de que os pacientes sejam tratados com os chamados medicamentos de segunda ou terceira linha, protegidos por patentes, atéagora importados. A parcela importadaé, atualmente, responsável por $81,6 \%$ das despesas.

\section{Os constrangimentos à oferta}

de antirretrovirais e a resposta nacional

Há, atualmente, uma aguda percepção sobre os constrangimentos - externos e internos - à política de ARV. No entanto, esses constrangimentos não são de agora. A trajetória do programa apresentou várias conjunturas críticas. Em 1999 e2000, a maxidesval orização do real ea potencial falta de recursos para a compra dos medicamentos no mercado internacional geraram preocupação quanto à sustentabilidade da política ${ }^{16}$.

Em agosto de 2001, o Ministério da Saúde ameaçou decretar o licenciamento compulsório do nelfinavir, fabricado pela Roche. 0 processo não foi adiante pois a empresa concordou em reduzir o preço do medicamento em $40 \%$.

Em dezembro de 2003, nova ameaça de licenciamento dessa droga foi aventada. Em 2004, 0 governo brasileiro obteve redução de preços do próprio nelfinavir e de mais quatro medicamen- tos, ten ofovir, atazanavir, lopinavir e efavirenz. 0 valor total do abatimento foi da ordem de $37 \%$.

Em junho de2005, o presidenteda República chegou a assinar a declaração de interesse público do Kaletra (lopinavir/ritonavir), fabricado pelo laboratório Abbott, primeiro passo legal para a decretação do licenciamento compulsório por questões de saúde pública. Porém, negociações posteriores levaram à redução de preço do antirretroviral, que foi considerada satisfatória pelo então ministro da Saúde ${ }^{16}$.

Nos embates, as indústrias também utilizam os recursos quel hes são facultados. N a negociação relativa ao Kaletra, antea possi bilidade da emissão da licença compulsória, representantes da indústriafarmacêutica desencadearam fortepressão junto ao Escritório Federal de Comércio dos EUA para que fossem adotadas contra o Brasil sanções comerciais em outros setores industriais ${ }^{17}$.

Em maio de 2007, pela primeira vez o país levou a cabo o licenciamento compulsório de uma droga - o efavirenz, produzido pelo laboratório M erck Sharp \& Dohme e comercializado sob o nome de Stocrin. A medida foi tomada após cinco meses de negociações consideradas infrutíferas. Foi utilizado 0 argumento do interesse público, previsto tanto no Acordo sobreos Aspectos dos Direitos de Propriedade I ntelectual Relativos ao Comércio (Trips) quanto na Lei de Propriedade Industrial brasileira ${ }^{18}$.

Dentre os importados, esse medicamento éo mais usado, sendo administrado a $38 \%$ dos pacientes em tratamento de Aids. Segundo o Programa Nacional de DST eAids (PN-DST/Aids) ${ }^{19}$, a medida permitiria a redução de $72 \%$ no preço do remédio ea economia de US\$30 milhões por ano. A versão genérica do medicamento passará a ser importada da Índia, de laboratórios certificados pela O M S, ao valor de U $\$ \$, 45$ por comprimido de $600 \mathrm{mg}$. Conforme as legislações internacional e brasileira, o país pagará royalties à empresa, estabelecidos em 1,5\% sobre o valor do genérico importado ou produzido no Brasil.

0 Acordo Trips, estabelecido pela Organização Mundial do Comércio (OMC) em 199420, pode representar o principal constrangimento formal à produção local de medicamentos ARV. Eledetermina, essencialmente, a proteção da propriedadeintelectual eo reconhecimento do direito ao uso, em regime de monopólio da patente, por determinado período de tempo. Em caso de ruptura, o país fica submetido a sanções legais e unilaterais no comércio internacional. Esse acordo também estabel ece flexi bilidades, permitindo o licenciamento compulsório nos casos em que 
se configure emergência nacional ou abuso de poder econômico. A Declaração de Doha, de 2001, trouxe uma abertura ao Acordo Trips; reconhece o direito dos países membros de estabe lecerem medidas para a proteção da saúde pública, incluindo, em especial, o acesso a medicamentos. Isso pode reforçar as decisões relacionadas às políticas de ampliação do acesso aos ARV por países não produtores.

A adesão do país ao Trips levou à promulgação da Lei de Propriedade Intelectual brasileira, deno 9.279/9621, em vigor em 15 demaio de 1997. Esta lei determina que os medicamentos resultantes de processo de inovação tenham suas patentes protegidas a partir dessa data, se produzidos no Brasil ou não. As drogas existentes até então não estavam submetidas a essa lei, podendo ser produzidas por outros laboratórios. Portanto, os ARV fabricados a partir de 1997, ou seja, todos os de segunda e terceira linhas, só podem ser produzidos pelas empresas detentoras das patentes. 0 acordo Trips franqueava ao país a implementação de proteção patentária apenas em 2005.

0 Quadro 1 exibe os medicamentos por classe terapêutica, evidenciando a fonte de produção, nacional ou importada.

$\mathrm{Na}$ conjuntura inicial de implementação da política de ARV, a principal estratégia brasileira foi a produção doméstica dos medicamentos que não estavam sujeitos à legisl ação de propriedade intelectual, ressalvando-se que a matéria-prima necessária é importada. Em segundo lugar, pressionar os laboratórios para baixar o preço das drogas protegidas por patentes utilizando-se da ameaça de licenciamento compulsório, dirigida às multinacionais farmacêuticas.

É possível supor que a impossibilidade de sustentar a provisão de ARV esteja colocada desde o início da política. Não houve, por parte do governo, o estabelecimento de estratégia de longo prazo para a sua sustentabilidade. A sustentabilidade pode ter sido ameaçada desde a conformidade ao Trips, sem moratória, o que reduziu o tempo que o Brasil teria para aumentar suas condições de autonomia como país produtor.

As saídas propostas pelos principais estudos que problematizam a sustentabilidade contemplam a ruptura com as regras do jogo. Grangeiro et al. afirmam, por exemplo, que a não utilização das prerrogativas previstas nos acordos sobre propriedade intelectual, como a licença compulsória, pode ter colaborado também para 0 aumento dos gastos com anti-retrovirais. 0 governo alterou a legislação sobre o tema em 2003, permitindo a importação de medicamentos genéricos, e decretou em 2004 a utilidade pública do medica-

Quadro 1. ARV distribuídos no Brasil em 2007, por categoria.

\begin{tabular}{|l|l|l|}
\hline \multicolumn{1}{|c}{ Categoria terapêutica } & Medicamento & Fonte de produção \\
\hline \multirow{4}{*}{ ITRN } & Zidovudina & Local \\
\cline { 2 - 3 } & Estavudina & Local \\
\cline { 2 - 3 } & Didanosina & Local \\
\cline { 2 - 3 } & Lamivudina & Local \\
\cline { 2 - 3 } & Abacavir & Importado \\
\hline \multirow{4}{*}{ IP } & Didanosina EC & Importado \\
\cline { 2 - 3 } & Tenofovir & Importado \\
\cline { 2 - 3 } & Ritonavir & Local \\
\cline { 2 - 3 } & Saquinavir & Local \\
\cline { 2 - 3 } & Indinavir & Importado \\
\cline { 2 - 3 } & Nelfinavir & Importado \\
\cline { 2 - 3 } & Amprenavir & Importado \\
\cline { 2 - 3 } & Lopinavir/r & Importado \\
\hline ITRNN & Atazanavir & Local \\
\hline \multirow{4}{*}{ Inibidor de fusão } & Nevirapina & Importado \\
\cline { 2 - 3 } & Efavirenz & Importado \\
\hline
\end{tabular}

Fonte: Programa Nacional deDST eAids. 
mento Lopinavir/Ritonavir, primeira etapa legal visando o licenciamento compulsório. A falta de maior determinação política governamental, nesse aspecto, enfraqueceu o poder de negociação do Ministério da Saúde, assim como lançou dúvidas sobre a capacidade da produção nacional de novas drogas $^{15}$.

\section{A estratégia do licenciamento compulsório}

O licenciamento compulsório do efavirenz abriu um novo capítulo na estratégia brasileira, que modifica a trajetória da política e cujas consequências ainda estão em discussão. A medida teve grande repercussão na mídia nacional e internacional. Segundo a Agência de N otícias da Aids ${ }^{22}$, no dia seguinte ao decreto que licenciou a droga, a seção Notícias do sítio de buscas Google, nos Estados Unidos, contabilizou mais de 346 reportagens sobre 0 assunto, apenas na América do Norte e no Reino Unido. No Brasil, a matéria foi veiculada nos meios de comunicação de todo 0 país ${ }^{23}$.

As declarações dividem os que apoiam a medida e os que a desaprovam. Jornais, acadêmicos, organizações não governamentais (ONGs) nacionais e internacionais estão entre os que argumentam que o governo brasileiro priorizou a saúde em detrimento dos interesses comerciais, além degarantir a sustentabilidade da política de medicamentos para a $\mathrm{Aids}^{23}$.

Já o editorial do Wall Street Journal entende que o licenciamento ameaça a capacidade da indústria farmacêutica de produzir novos medicamentos e conclamou a OMS a pronunciar-se contra as decisões de Brasil eTailândia ${ }^{24}$. Um dos diretores-gerentes da Câmara de Comércio dos EUA declarou que o Brasil "decidiu se igualar à junta militar que comanda a Tailândia e quebrar a patente" eque será difícil manter o país no Sistema Geral de Preferências, programa de benefícios fiscais pelo qual o Brasil exporta US\$ 3,5 bilhões anualmente para os EUA ${ }^{25}$.

O uso do licenciamento compulsório não é recebido de maneira uniformeno contexto internacional. EUA e Canadá já se beneficiaram da medida quando isso atendeu aos seus interesses públicos. Em 2005, a Itália decretou o licenciamento compulsório do antibiótico Tienam, da própria M erck ${ }^{17,26}$. As situações em que países do Primeiro Mundo emitem o licenciamento compulsório não geram debates intensos. Em primeiro lugar, pela própria assimetria entre países, que propicia que estados poderosos possam se valer das flexibilidades previstas com mais facilidade que outros. Além disso, por serem países produtores, não se supõe que agirão contra si mesmos promovendo o desrespeito sistemático à propriedade intelectual.

No caso dos antirretrovirais, M oçambique, M alásia, Indonésia e Tailândia já se utilizaram dessa flexibilidade prevista no Trips. Não houve polêmica quanto aos três primeiros, mas o caso da Tailândia gerou reações. Em novembro de 2006, esse país decretou o licenciamento do Efavirenz e, em março de 2007, o do Kaletra. Como represália, a Abbott suspendeu o registro de sete novas drogas, incluindo o Aluvia, nova versão do Kaletra, resistente ao calor e que elimina os altos custos de refrigeração para a sua conservação. Além disso, a Tailândia foi incluída em uma "lista de prioridades", emitida por entidades comerciais dos EUA, composta por países que requerem observação por enfraquecerem o respeito às patentes ${ }^{27}$. Contudo, nenhum dos casos de licenciamento citados aqui foi levado à $\mathrm{OMC}$, pois foram efetuados dentro das condições eformalidades estipuladas pela legislação vigente.

A controvérsia diz respeito ao estabelecimento de parâmetros razoáveis para países emergentes e de renda média, como o Brasil ea Tailândia, que não têm o poder aquisitivo dos países centrais, mas que podem pagar mais do que os de renda baixa. Além disso, ambos se tornaram lideranças entre os países em desenvolvimento e exemplos de estados que privilegiaram as políticas domésticas de proteção à saúdeem detrimento das pressões externas. As grandes companhias e as entidades ligadas ao comércio internacional temem que tais iniciativas estimulem outras, enfraquecendo a legislação patentária.

No contexto mundial, entretanto, as perspectivas são de agravamento do constrangimento formal pela multiplicação de tratados de livre comércio bilaterais e regionais entre países. Vários destes preveem condições de proteção patentária mais restritas do que o Trips, deixando países não produtores em desvantagem ainda maior ${ }^{28}$. É 0 caso dos acordos EUA-Chile, EUA-Cingapura, EUA-Jordânia e Tratado de Livre Comércio da América do Norte ( $\mathrm{Nafta)}$, dentre outros.

Cabe ressaltar outra faceta da dinâmica internacional, visto que a partir de década de 2000 a oferta de ARV tomou âmbito mais amplo. H ouve uma clara inflexão no sentido do reconhecimento dos antirretrovirais como essenciais na luta contra a Aids, e o Brasil foi um dos países líderes na articulação pelo acesso aos ARV nos foros internacionais. Em 2001, a Comissão de 
Direitos Humanos da Organização das Nações Unidas (ONU) postulou o acesso a medicamentos ARV como direito humano à saúde. Nesse mesmo ano, realizou-se a Sessão Extraordinária da Assembléia Geral das Nações Unidas sobre HIV eAids, que reputa que o enfrentamento da epidemia deve associar prevenção, assistência e promoção dos direitos humanos. Ainda em 2001 foi criado o Fundo Global de Combate contra HIV/Aids, Tuberculose e M alária, queéuma iniciativa internacional que congrega governos, sociedadecivil, setor privado e comunidades afetadas em um fundo destinado a financiar ações de controle das doenças, incluindo tratamento ${ }^{29}$. Em 2003, a OMS publicou diretrizes para o uso de ARV em países em desenvolvimento ${ }^{30}$ elançou 0 programa 3-by-5, cujo objetivo era ofertar tratamento a três milhões de pessoas com HIV/Aids até $2005^{31}$. Atores mais recentes se incluíram no cenário, como a Fundação Clinton, que tem entre seus objetivos a negociação de drogas antiHIV/Aids a preços mais baixos para os países mais pobres. Contudo, no final de 2005, não mais de 1,3 milhão de pessoas recebiam ARV em países de renda média e baixa ${ }^{32}$. Por sua vez, o Fundo Global apresentava, em fins de2006, um déficit de US\$2,1 bilhões, quase a metade dos US\$ 5,5 bilhões necessários para financiar doações novas e as já em andamento ${ }^{33}$. A pesar da expansão de gestões e recursos econômicos, constatase que a necessidade de países de renda média e baixa não vem sendo atendida. Ademais, os atores citados não questionam as regras formais vigentes em favor da ampliação da oferta deARV, ou seja, são aderentes aos acordos internacionais, incluindo a proteção patentária. Suas ações se dão através do incentivo a doações ou à intermediação para segmentação de preços, que prevêa estipulação deles de acordo com a renda do país. Assim, embora tenham relevância na ampliação do acesso aos ARV e apoiem o "ideário do acesso", não interferem na arena das regras formais que regem o mercado internacional.

Muitos dos que defendem a decisão do governo brasileiro quanto ao licenciamento do efavirenz apontam para um ponto crucial do debate, que é a capacidade do país de produção de ARV. No caso do efavirenz, sua formulação genérica passará a ser comprada da Índia, o que ainda mantém o Brasil em posição de dependência. Como citado anteriormente, as duas principais estratégias brasileiras para a manutenção da política de fornecimento deARV vinham sendo, em primeiro lugar, a produção nacional dos remédios de patente livre e, em segundo, a pres- são junto aos laboratórios internacionais para a redução de preços de medicamentos de patente protegida. No entanto, o segundo componente está intrinsecamente vinculado ao primeiro. Para quea ameaça de licenciamento compulsório seja utilizada de forma crível, é necessário que a produção seja viável. 0 manejo dessas estratégias é fundamental para a sustentabilidade da política brasileira, e o cenário não deverá se alterar completamenteapóso decreto do licenciamento compulsório do efavirenz. 0 recurso a essa medida terá de ser preservado para as situações limite e não levado a cabo como uma política em si.

No início da política de oferta deARV, a produção de medicamentos por parte de laboratórios públicos como Farmanguinhos/Fiocruz, a Fundação para o Remédio Popular (Furp/SP), o Laboratório Farmacêutico do Estado dePernambuco (Lafepe) e a Fundação Ezequiel Dias (Funed) foi crucial para que a iniciativa fosse bemsucedida. No entanto, estudos mostram que a posição dessas unidades no mercado vem sofrendo mudanças importantes. A partir de 2003, a indústria farmacêutica empreendeu estratégia desubstituição deARV em favor da produção de uma segunda linha protegida por patentes. Essa estratégia buscou neutralizar as pressões governamentais e enfraquecer a regulação de comando e controle dos laboratórios oficiais pela produção direta do mercado ${ }^{34}$. 0 processo substitutivo foi, portanto, favorecido pelas novas condições institucionais criada pela Lei de Patentes.

Corroborando dados já mencionados neste artigo, Grangeiro et al..$^{15}$ indicam queos gastos com ARV quasetriplicaram no período de 1998 a 2005. Nos dois primeiros anos, de 1998 e 1999, o gasto médio por paciente foi o maior de toda a série, atingindo $R \$ 7.781,00 \mathrm{em} 1999$. No período de 2000 a 2004 houve decréscimo e, em seguida, estabilização dos gastos. A partir de2005 estes aumentaram eessa tendência permanece, sem perspectiva dereversão. Para os autores, as razões que determinaram a estabilização dos gastos foram justamente a produção local de drogas e as negociações de preços bem-sucedidas. Porém, a falta de política efetiva para o setor enfraqueceu a indústria nacional. U ma das consequências foi 0 aumento dos preços das drogas produzidas no Brasil. Em 2000, os preços dos medicamentos produzidos no Brasil correspondiam, em média, a $91,8 \%$ do valor das drogas. Em 2005, os preços nacionais foram três vezes superiores aos preços mais baixos praticados no mercado mundial. Registrem-se, igualmente, faIhas no abastecimento de genéricos e similares e a redução da capacidade técnica das empresas naci- 
onais, que não incorporaram a fabricação de novas drogas surgidas a partir de 2001.

Costa e Castro ${ }^{34}$, em seu estudo sobre Farmanguinhos, analisam as posições de mercado dos laboratórios públicos. Os autores mostram como Farmanguinhos beneficiou-se das decisões do M inistério da Saúde para obter posição vantajosa sobre as demais unidades, em uma conjuntura favorável do SUS, que absorvia a produção das empresas oficiais para os programas públicos de oferta de medicamentos. Farmanguinhos orientou suas ações para a produção de medicamentos cuja produção não interessa ao setor privado pelo seu baixo retorno econômico - para o Programa Saúde da Família e os antirretrovirais para o PN-DST/Aids.

Se por um lado as condições de governança vertical propiciaram o acesso privilegiado ao orçamento federal do SUS, por outro enfraqueceram a análise de suas competências estratégicas e, consequentemente, sua posição no mercado público. A perda de posi ção de mercado também afetou os demais laboratórios públicos, apesar de Farmanguinhos ter apresentado o maior de créscimo. Os laboratórios públicos estaduais, especialmente o Lafepe e a Furp, têm apresentado notáveis esforços de inovação, que fortal eceram a sua competividade quando comparados à trajetória recente de Farmanguinhos ${ }^{34}$. A Tabela 1 mostra a distribuição percentual da produção de ARV de Farmanguinhos, dos demais laboratórios públicos e das empresas privadas, nacionais e estrangeiras, de 2001 a 2006. Em 2001, a soma da participação dos dois primeiros correspondia a $56 \%$, enquanto as empresas privadas (nacionais e estrangeiras) eram responsáveis por $44 \%$ dos medicamentos. Em 2006, a soma das públicas cai para 45\%, e o setor privado aumenta sua participação para 55\%.

A Tabela 2 demonstra que as empresas privadas aumentaram sua participação de 65,5\% para $81 \%$ nos gastos do PN-DST/Aids com medicamentos, de 2001 a 2006.

A precocidade da adesão ao Trips cerceou a autonomia decisória das empresas nacionais para 0 atendimento do interesse público. 0 Brasil dispunha de um período de transição de dez anos entre o estabelecimento do Trips ea promulgação

Tabela 1. Participação (\%) de Farmanguinhos, dos laboratórios oficiais e das empresas privadas na quantidade de medicamentos adquiridos pelo PN-DST/Aids (2001-2006).

\begin{tabular}{ccccc}
\hline Ano & \% Farmanguinhos & \% Laboratórios oficiais & $\%$ Empresas privadas & Total \\
\hline 2001 & 34 & 22 & 44 & 100 \\
2002 & 28 & 30 & 42 & 100 \\
2003 & 21 & 38 & 41 & 100 \\
2004 & 14 & 30 & 56 & 100 \\
2005 & 8 & 36 & 56 & 100 \\
2006 & 10 & 35 & 55 & 100 \\
\hline
\end{tabular}

Fonte: Instituto Tecnológico deFarmanguinhos- 2006 (citado em ${ }^{34}$ ).

Tabela 2. Participação (\%) de Farmanguinhos, dos laboratórios oficiais e das empresas privadas nos gastos com medicamentos do PN-DST/Aids (2001- 2006).

\begin{tabular}{ccccc}
\hline Ano & \% Farmanguinhos & \% Laboratórios oficiais & $\%$ Empresas privadas & Total \\
\hline 2001 & 25 & 9,5 & 65,5 & 100 \\
2002 & 17 & 19 & 64 & 100 \\
2003 & 11 & 22 & 67 & 100 \\
2004 & 5 & 13 & 82 & 100 \\
2005 & 4 & 17 & 79 & 100 \\
2006 & 4 & 15 & 81 & 100 \\
\hline
\end{tabular}

Fonte: Instituto Tecnológico deFarmanguinhos- 2006 ( citado em ${ }^{34}$ ). 
de uma lei de propriedade intelectual brasileira. Apenas três anos depois esta lei entrou em vigor. Desta forma, não houve tempo hábil para a adequação dos regimes tecnológicos das empresas públicas. Assim, a produção local de ARV, um dos pilares da política nacional, beneficiou-se do pequeno intervalo detempo entreo início da produção dos medicamentos até a efetivação da lei brasileira de propriedade intelectual, a partir da qual as drogas de segunda e terceira linhas não mais poderiam ser copiadas e produzidas.

China e Índia utilizaram todo o tempo disponível. Esta última, nova fornecedora do efavirenz para o Brasil, aderiu ao Trips apenas em 2005. Impulsionada por política de incentivo à indústria farmacêutica nacional desde a década de 70, as empresas públicas indianas detêm hoje três quartos do mercado nacional. No mercado mundial, oferecem um dos menores preços.

\section{Consideraçõesfinais}

Os esforços para controlar os gastos com as me dicações ARV e as reações ao licenciamento compulsório são evidências do alto grau de conflito normativo entre a política nacional de oferta dessas drogas e as regras institucionais supranacionais. Incluem-se nas últimas não apenas as regras formais, como o Trips, mas também as informais, como retaliações econômicas e o efeito da assimetria entre países. Contudo, a persistência na manutenção da oferta de medicamentos para Aids indica que há importante contraposição aos movimentos externos. A imagem positiva da política, expressada em seus progressos, gerou forte coesão nos âmbitos nacional e internacional. Internamente, a coalizão entre grupos da sociedade civil etécnicos expandiu-se, ea percepção favorável conquistou adeptos em todas as camadas sociais. Assim, não se verificou o efeito ônibus de adesão das elites técnicas e da burocracia às regras externas, de cunho restritivo.

Nos foros externos, especialmente junto aos organismos multilaterais, as gestões brasileiras foram hábeis em amplificar a imagem de pioneirismo, soberania e respeito aos direitos huma- nos. Além da visibilidadeinternacional, esse apoio tem sido importante no reforço da legitimação interna da política. Entretanto, a defesa do acesso aos ARV por parte dos organismos multilaterais afeta marginalmente as regras do comércio internacional, quando não as acata totalmente. Estas têm poder normativo incomparavelmente maior no cenário internacional.

A redefinição de forças gerada pelas questões depropriedadeintelectual edireito patentário tem tido grande efeito sobre a sustentabilidade da oferta de ARV. Os gastos parecem ser crescentes e, considerando-se a estratégia substitutiva da indústria farmacêutica, não há perspectiva de reversão dessa tendência sem a reorientação de ações. Do ponto de vista da assistência farmacêutica no país, o grande peso orçamentário desses medicamentos ante os demais tem aumentado as preocupações dos gestores federais. No debate interno, a adesão à distribuição universal e gratuita das drogas anti-HIV/Aids é hegemônica e suplanta seus antagonistas. Porém, considerando-se a elevação proporcional dos gastos, não se pode garantir que não haverá mudança de posição dos atores relevantes.

Políticas públicas, de distribuição universal e gratuita como a dosARV, não podem ser mantidas em condições de monopólio de produção. Considerando que a principal barreira de mercado é institucional e não tecnológica, o Estado deverá decidir entre a manutenção da regra de monopólio e a eficiência al ocativa.

Um mercado é competitivo se os consumidores podem escolher entre uma ampla variedade de produtos com características similares, e se as empresas não encontram obstáculos para ofertar produtos eserviços. O licenciamento compulsório não constitui estratégia de ampliação de competitividade. É essencial que as novas medidas institucionais sejam tomadas pelo governo brasileiro em relação à competitividade. 0 M inistério da Saúdedevefavorecer as condições deaquisição dos produtos e serviços em condições de competição. Como consequência, os laboratórios oficiais e os produtores nacionais poderão se posicionar no mercado, sem que haja obstáculos institucionais para a oferta de medicamentos. 


\section{Colaboradores}

RF Lago e NR Costa participaram igualmente de todas as etapas da elaboração do artigo.

\section{Referências}

1. Teixeira PR, Vitória MA, Barcarolo J. Antiretroviral treatment in resource-poor settings: the Brazilian experience. Aids 2004; 18(Suppl.):S5-S7.

2. North DC. Institutions, institutional change and economic performance. Cambridge: Cambridge University Press; 1990.

3. M elo MA, Costa NR. Desenvolvimento sustentável, ajuste estrutural e política social: as estratégias da OMS/OPS e do Banco Mundial para a atenção à saúde. Planejamento e políticas públicas (I pea) 1994; 1:49-108.

4. Barros E. Brasil: Programa de dispensação de medicamentos em caráter excepcional: relatório de estudo de caso. Projeto: Efetividade do desenvolvimento em saúde: experiências exitosas na América Latina e Caribe. Campinas: NEPP/Unicamp/BID; 2006.

5. Brasil. Lei no 9.313, de 13 de novembro de 1996. Dispõe sobre a distribuição gratuita de medicamentos aos portadores do HIV e doentes de Aids. Diário O ficial da União 1996. [acessado 2007 set 29]. Disponível em: http://www.pge.sp.gov.br/centrodeestudos/ bibliotecavirtual/dh/volume\%20i/saudel ei9313.htm

6. Greco D, Simão M. Brazilian policy of universal acces to Aids treatment: sustainability challenges and perspectives. Aids 2007; 21(Suppl.4):S37-S45.

7. Marins JR, Jamal LF, Chen SY, Barros MB, Hudes ES, Barbosa AA, Chequer P, Teixeira PR, Hearst N. Dramatic improvement in survival among adult Brazilian Aids patients. Aids 2003; 17:1675-1682.

8. Portela MC, Lotrowska M. Assistência aos pacientes com HIV/Aids no Brasil. Rev Saude Publica 2006; 40(Supl.): $70-79$.

9. World Bank. Aids and STD Control Project I and II. Project Performance Assessment Report. Washington, D.C.: World Bank; 2004.

10. Parker R, Mattos RA, Terto Jr V. As estratégias do Banco $M$ undial e a resposta brasileira à Aids no Brasil. In: Barros F, organizador. As estratégias dos bancos multilaterais para o Brasil (2000-2003). Brasília: Rede Brasil; 2001.

11. Oliveira Cruz V, Kowalski J, M cPake B. Viewpoint: the Brazilian HIV/Aids "success story" - can others do it? Trop Med Int Health 2004; 9:292-297.

12. Levi GC, Vitória MA. Fighting against Aids: the Brazilian experience. Aids 2002; 16:2373-2383.

13. Serra J. The political economy of the Brazilian struggle against Aids. Princeton: The Institute for Advanced Study; 2003. [mimeo].

14. N unn A, Fonseca EM, Bastos FI, Gruskin S, Salomon JA. Evolution of antiretroviral drug costs in Brazil in the context of free and universal access to aids treatment. PLOS M edicine 2007; 4(11):e305.

15. Grangeiro A, Teixeira L, Bastos IF, Teixeira P. Sustentabilidade da política de acesso a medicamentos anti-retrovirais no Brasil. Rev Saude Publica 2006; 40(Supl.):60-69.

16. Brasil. M inistério da Saúde. Agência de Notícias da Aids. Histórico do Programa Nacional de DST e Aids. In: Programa Nacional de DST e Aids - Ministério da Saúde; 2007. [acessado 2007 maio 20]. Disponível em: http://www.aids.gov.br 
17. Chaves GC. Patentes farmacêuticas: por que dificultam 0 acesso a medicamentos? Rio de Janeiro: Associação Brasileira Interdisciplinar de Aids; 2006.

18. Penna G, Simão M. Nota de esclarecimento. In: Programa Nacional de DST e Aids, Ministério da Saúde; 2007. [acessado 2007 maio 20]. Disponível em: http://www.aids.gov.br

19. Brasil. Ministério da Saúde. Programa Nacional de DST e Aids. Brasil decreta licenciamento compulsório do efavirenz. Notícias do Programa Nacional; 2007. [acessado 2007 maio 20]. Disponível em: www.aids.gov.br

20. WTO. Agreement on trade-related aspects of intellectual property rights. World Trade Organization; 1994. [acessado 2007 abr 13]. Disponível em: http:// www.wto.org/english/tratop_e/trips_e/t_agm0_ e.htm

21. Brasil. Lei no 9.279, de 14 de maio de 1996. Regula direitos e obrigações relativos à propriedade industrial. M inistério do Desenvolvimento, Indústria e Comércio Exterior. Diário Oficial da União 1996. [acessado 2005 set $1^{\circ}$ ]. Disponível em: http:// www.inpi.gov.br

22. Brasil. Agência de Notícias da Aids. Atitude do governo brasileiro frente a M erck é destaque na mídia internacional. In: Programa Nacional de DST e Aids - Ministério da Saúde; 2007. [acessado 2007 maio 20]. Disponível em: http://www.aids.gov.br

23. Lula fez bem ao quebrar a patente de um medicamento para Aids? 0 Estado de S. Paulo 2007; 13 maio.

24. BBC Brasil. Quebra de patente anti-Aids é “jogo perigoso", diz Wall Street. [acessado 2007 maio 20]. Disponível em: http://www.aids.gov.br

25. D'Ávila S. Brasil se igualou à junta militar da Tailândia. Folha de S. Paulo 2007; 6 mai.

26. Costa AL. Guerra pela vida. Carta Capital 2007; 13 mai.
27. M ongkol to chair of UNAids from next month. The Nation 2007; 21 maio.

28. Beattie A, Jack A, Kazmin A. Patent or patient? H ow Washington uses trade deals to protect drugs. Financial Times 2006; 22 ago.

29. The Global Fund to Fight Aids tuberculosis and malaria. 2005. [acessado 2005 set 2]. Disponível em: http://www.theglobalfund.org/en/

30. World Health Organization (WHO). Scaling up antiretroviral therapy in resource-limited settings: treatment guidelines for a public health approach; 2003. [acessado 2007 ago 2]. Disponível em: http:// whqlibdoc.who.int/hq/2004/9241591552.pdf

31. World Health Organization (WHO); 2005. [acessado 2006 set 2]. Disponível em: www.who.int/3by5/en/

32. Gilks CF, Crowley S, Ekpini R, Gove S, Perriens J, Souteyrand D, Vitoria M, Guerma T, De Cock K. The WHO public-health approach to antiretroviral treatment against HIV in resource-limited settings. Lancet 2006; 368:505-510.

33. The business of HIV/Aids. Lancet 2006; 368:423.

34. Costa NR, Castro AJW. Custos de transação, estraté gias de inovação e produção de medicamentos em laboratórios públicos: 0 caso do Instituto Tecnológico de Farmanguinhos. Rio de Janeiro: Escola Nacional de Saúde Pública Sergio Arouca, Fundação Oswaldo Cruz; 2007

Artigo apresentado em 19/11/2007

Aprovado em 07/03/2008

Versão final apresentada em 31/03/2008 